\title{
Editorial
}

\section{Depression, Suicidal Ideation, and Resilience among Rural Farmers}

India currently ranks $19^{\text {th }}$ in rates of suicide worldwide, ${ }^{[1]}$ and while increasing amount of attention is being paid by health workers and legislators toward the need to identify and ameliorate factors responsible, the subgroup of farmers in India has shown particularly higher rates of suicide $^{[2]}$ and the suicides have been subject to a significant amount of political debate, inquiry commissions and recommendations: ${ }^{[2]}$ however, what results have been gained, is a question still not answered adequately.

The authors' attempt in the current manuscript ${ }^{[3]}$ of trying to identify the hardships of farmers in rural South Indian community and to identify features of their mental status in light of drought is commendable. It should be noted that the phenomena of farmers suicide is not isolated to certain belts but has been reported from all around the country, including Maharashtra, Uttar Pradesh, Punjab, Andhra Pradesh, etc. ${ }^{[4]}$ and also in Western countries. ${ }^{[5]}$ A concern, however, still remains that while suicides in this subgroup generates vehement discussions and political activity, resulting in some socioeconomic measures by the governments, attempts at linking the act to mental health status and providing steps to tackle this aspect of the problem are largely lacking.

In-depth analyzes into farmers' suicide in India ${ }^{[6]}$ shows that these are caused by a nexus of inter-related causes. These include marginal returns on farmland, lack of diversification of income streams, indebtedness, crop failure, loss of social status, or failure to fulfill expected societal roles among others. The study also identified an apparent imitation phenomenon where recent suicides in vicinity were found to be linked to higher number of suicides. Similarly, a significant association was found between comorbid physical and psychiatric ailments of the farmers and their substance (alcohol) use.

While the current understanding of the issue dictates that farmers' suicides are not exclusively a mental health issue ${ }^{[4]}$ and it has been constantly argued that farmers' suicide are a part of much larger problem of agricultural crises, ${ }^{[7]}$ from public health perspective, one should note that most of these factors are also identified as major predictors of suicidal acts in general public at large. ${ }^{[8]}$ The farmer community seem to be at an increased risk of exposure to these factors and hence form a vulnerable population. It can be argued that all these factors, interplaying with personal situation and disposition of an individual would have significant impact on mental health.

The current article clearly demonstrates that the prevalence of depressive symptoms is very high in their sample, in fact, more that $90 \%$ of the sample reported depressive symptoms. This provides us with a pragmatic intervention potential where along with the measures undertaken by governments on the socioeconomic front, making use of the community mental health services can be offered. While it would be overly optimistic to hope that only mental health interventions will be enough to ameliorate the conditions of the farmers, research endeavors like the current article clearly show that it is a need that cannot be ignored.

Kabir Garg
Community Mental Health Services, Hertfordshire Partnership
NHS Foundation Trust, Hertfordshire, UK
Address for correspondence: Dr. Kabir Garg,
NHS Foundation Trust, Hertfordshire, UK.
E-mail: kabirindian2007@gmail.com

\section{REFERENCES}

1. World Health Organization, editor. In: Reporsitory GHOd. World Health Organization; 2018.

2. Behere PB, Behere AP. Farmers' suicide in Vidarbha region of Maharashtra state: A myth or reality? Indian J Psychiatry 2008;50:124-7.

3. Viswanathan DJ, Veerakumar AM, Kumarasamy H. Depression, suicidal ideation, and resilience among rural farmers in a drought-affected area of Trichy District, Tamil Nadu. J Neurosci Rural Pract 2019;10:241-7.

4. Behere PB, Bhise MC. Farmers' suicide: Across culture. Indian J Psychiatry 2009;51:242-3.

5. Hawton K, Fagg J, Simkin S, Harriss L, Malmberg A. Methods used for suicide by farmers in England and Wales. The contribution of availability and its relevance to prevention. Br J Psychiatry 1998;173:320-4.

6. Mishra S. Risks, farmers' suicides and agrarian crisis in India: Is there a way out? $67^{\text {th }}$ Annual Conference of the Indian Society of Agricultural Economic; Lucknow: Indira Gandhi Institute of Development Research; 2012

7. Das A. Farmers' suicide in India: Implications for public mental health. Int J Soc Psychiatry 2011;57:21-9.

8. Arya V, Page A, River J, Armstrong G, Mayer P. Trends and socio-economic determinants of suicide in India: 2001-2013. Soc Psychiatry Psychiatr Epidemiol 2018;53:269-78.

This is an open access journal, and articles are distributed under the terms of the Creative Commons Attribution-NonCommercial-ShareAlike 4.0 License, which allows others to remix, tweak, and build upon the work non-commercially, as long as appropriate credit is given and the new creations are licensed under the identical terms.

\begin{tabular}{|l|l|}
\hline \multicolumn{2}{|c|}{ Access this article online } \\
\hline Quick Response Code: & Website: \\
\hline & \\
\cline { 2 - 2 } & \\
\hline
\end{tabular}

How to cite this article: Garg K. Depression, Suicidal Ideation, and Resilience among Rural Farmers. J Neurosci Rural Pract 2019;10:175. 